\title{
Análise ergonômica do trabalho agrícola familiar na produção de leite
}

\author{
Uiara Bandinel Montedo \\ Laerte IDal Sznelwar \\ EPUSP
}

\section{Resumo}

Este artigo trata da metodologia utilizada em uma intervenção ergonômica sobre organização do trabalho em Unidades de Produção Agrícola Familiar (UPAF) produtoras de leite de origem bovina, na região oeste da França. Apresenta-se a metodologia utilizada, uma combinação de jornadas de observação e análise do trabalho e jornadas de formação-ação. Discutem-se a Crônica de Ação e o Plano de Utilização das Instalações (PUI), bem como a utilização destes no processo de conscientização do agricultor sobre a complexidade de seu trabalho. Apresenta-se a análise da "supervisão do rebanho", devido ao seu alto grau de complexidade e importância para o desempenho da produção de leite, explorando de que forma certos arranjos espaciais podem favorecer as condições para a realização desta tarefa. $\mathrm{Na}$ análise do trabalho agrícola familiar privilegia-se o olhar complexo sobre a situação de trabalho, visando identificar os determinantes, as fontes de variabilidade e as estratégias adotadas.

\section{Palavras-chave}

Ergonomia agrícola, análise ergonômica do trabalho, complexidade, agricultura familiar

\section{The ergonomic work analysis of dairy family farmers}

\begin{abstract}
This paper discusses the methodology of an ergonomic intervention applied on dairy family farming production units (FFPU) based in Western France. Contents include a description of the methodology, the combination of observation sessions and work analysis, as well as learning-action sessions. The Action's Chronicle and the Plan of Buildings Destination (PBD) are analyzed considering their influence on farmer's awareness about the complexity of dairy production activity. Since herd monitoring is a very complex practice and has huge impact on milk productivity, the influence of herd spatial distribution on working conditions is considered carefully. The complexity theory approach is applied in order to identify the causes, the sources of variability and the strategies adopted by dairy farmers.
\end{abstract}

Key words

Agricultural ergonomics, ergonomic work analysis, complexity 


\section{INTRODUĈ̣̃O}

O presente artigo trata da realização de uma intervenção ergonômica sobre a organização do trabalho em dezUnidades de Produção Agrícola Familiar (UPAF) no Departamento de Mayenne (região oeste da França), cuja produção principal é a de leite de origem bovina (MONTEDO, 2001).

Acredita-se ser sua principal contribuição aquela de detalhar aspectos da metodologia utilizada para tal intervenção, uma vez que o trabalho agrícola familiar apresenta características que lhe são intrínsecas e que podem ser analisadas a partir do ponto de vista da Teoria da Complexidade, proposta por Morin (1998).

Desde a realização das observações iniciais do trabalho dos agricultores, percebeu-se que a situação de trabalho agrícola familiar era rica em elementos que lhe conferiam características - tais como imprecisão, riqueza em imprevistos e acontecimentos aleatórios, imbricação de tarefas em um ambiente dinâmico cujo estado podia variar sem a interferência do agricultor. Ora, para que a explicação da realidade do trabalho fizesse sentido para o agricultor, ela teria que passar pela explicação complexa, pois este ator já está acostumado a lidar na prática com esta complexidade.

Percebeu-se então que, para compreender a situação de trabalho agrícola familiar e para poder construir com o agricultor uma melhor compreensão de sua atividade de trabalho, o ergonomista lança mão, embora intuitivamente, do olhar complexo sobre a situação de trabalho.

A Análise Ergonômica do Trabalho (AET) leva a identificar uma série de elementos que modulam a atividade de trabalho, em níveis diversos, com conseqüências também em diversos níveis. A todo o momento analisa-se de que forma a atividade de trabalho integra estes elementos e como diferentes racionalidades, que permeiam a construção deste sistema, se manifestam. A diversidade destes elementos, ou variáveis que interferem no trabalho, requer um olhar complexo, que pode permitir um movimento de "costura" das diversas dimensões ali presentes, reconstituindo o tecido da complexidade que envolve a situação de trabalho, para que a explicação do ergonomista faça sentido, para ele mesmo e, principalmente, para os trabalhadores.

Assim, o presente artigo pretende apresentar e discutir uma metodologia própria, baseada na AET dentro de um processo de formação-ação (ESCOUTELOUP, MARTIN, BARTHELOT, 1996), voltada para a análise do trabalho agrícola em unidades de produção familiar. Propõe-se incorporar um olhar complexo como um paradigma constitutivo das abordagens do trabalho, em especial a análise da atividade. Coloca-se em evidência a análise da tarefa "supervisão do rebanho", por ser esta de fundamental importância para o desempenho da unidade de produção, além de possuir propriedades para bem representar esta proposta. Procura-se mostrar como esta tarefa encontra-se imbricada nas demais, utilizando ferramentas como a Crônica de Ação e o Plano de Utilização das Instalações (PUI).

\section{METODOLOGIA}

A demanda formulada pelos agricultores (e reformulada pelos ergonomistas) era a de poder intervir no projeto de adequação de suas Unidades de Produção Agrícola Familiar (UPAF) às Normas Ambientais da Política Agrícola Comum (PAC) da Comunidade Econômica Européia (CEE), fazendo com que cada projeto levasse em consideração os objetivos de cada agricultor, dentre eles, a melhoria das condições de trabalho.

Acontece que, paradoxalmente, os agricultores sentiam-se despreparados para enfrentar o processo de elaboração dos projetos com os técnicos, não tendo argumentos para fazer valer o ponto de vista do trabalho no projeto; sentiam-se intimidados pela abordagem tecnicista e sua linguagem. Se, no entanto, o agricultor não fosse o portador do ponto de vista do trabalho real no projeto, quem o seria? Um projeto dirigido apenas pela racionalidade técnica, sem considerar a racionalidade do trabalho, fatalmente levaria a conseqüências, senão indesejadas, no mínimo imprevisíveis, sobre as futuras condições de trabalho. Assim, fortalecer a posição do agricultor familiar enquanto ator de seu projeto, enquanto portador do ponto de vista do trabalho real no projeto, tornava-se imperativo para satisfazer a demanda que se propunha.

Fazia-se a hipótese de que o agricultor introjeta o ponto de vista dominante na sociedade sobre o seu trabalho: aquele de que há pouca necessidade de atividade intelectual para a realização de sua atividade profissional. Isto faz com que a complexidade de sua atividade e as estratégias que adota para realizá-la permaneçam tácitas, ou até inconscientes, não sendo objeto de verbalização e apropriação coletiva por parte dos agricultores; ou que esta complexidade e as estratégias adotadas permaneçam desconhecidas, ignoradas e desprezadas pelos cidadãos que vivem nas cidades e até mesmo nos municípios rurais, que tendem a valorizar sobremaneira o ensino formal em detrimento do saber prático, do "saber fazer" característico do trabalho agrícola.

Como afirma Wisner (1996): “a atividade intelectual dos agricultores é na maioria das vezes ignorada, negada ou desprezada devido em parte a seu caráter concreto. A escola, de quem não nego o papel essencial, tem, no entanto, o defeito de valorizar excessivamente seu produto, o trabalho intelectual formal, as atividades escolares às expensas das atividades concretas, dos problemas que elas colocam e da dificuldade de encontrar as soluções eficazes. A inteligência dos agricultores emana da cognição situada, aquela que, a todo instante, tende a considerar todos os elementos da situação necessários para encontrar a melhor maneira de agir". 
Considerando estes elementos sugeriu-se, então, realizar uma formação-ação sobre a organização do trabalho agrícola familiar, cujas discussões em grupo seriam alimentadas por dados retirados de jornadas de observação e análise do trabalho, que seriam efetuadas em cada uma das dez unidades de produção. O objetivo desta proposta era o de construir com os agricultores uma representação de seu trabalho mais próxima ao trabalho real, construindo também um conjunto de argumentos para auxiliá-los no planejamento do trabalho futuro, além de uma ferramenta que serviria como objeto intermediário de concepção (JEANTET et al., 1996) no futuro projeto. Nossa hipótese era a de que fortalecendo, por um lado, a representação do trabalho com base no trabalho real e, por outro lado, o discurso dos agricultores em relação ao seu próprio trabalho, estar-se-ia auxiliando-os a se tornarem "pilotos" de seus projetos e a trazer, para este processo, o ponto de vista do trabalho real, antecipando as conseqüências das decisões a serem tomadas sobre as futuras condições de trabalho. lápis, anotações estas que procuravam seguir o desenvolvimento espacial, temporal e cronológico da ação. Todo intervalo (para o café da manhã, lanche, etc.) foi aproveitado para realizar a autoconfrontação com o agricultor, dando sentido às observações, pois em geral passava-se um dia e uma noite em cada uma das unidades de produção, sendo o tempo para autoconfrontação relativamente escasso. Esta abordagem permitiu a construção de Crônicas de Ação, elaboradas a partir do desenrolar dos acontecimentos de uma jornada de observação. Estas Crônicas eram utilizadas nas sessões de autoconfrontação, possibilitando a reconstrução de histórias a partir de acontecimentos marcantes ocorridos durante a jornada de observação, significativos do ponto de vista de suas conseqüências, reais ou potenciais, sobre a organização do trabalho, a eficiência da produção e a saúde da equipe de trabalhadores. Algumas destas histórias seriam colocadas em circulação por ocasião das jornadas de formação-ação, nas quais eram discutidas pelo grupo de dez agricultores.

Ao final de cada uma das jornadas (ou durante uma parte da tarde, dependendo do planejamento do trabalho feito pelo agricultor) realizava-se a co-construção (entre o agricultor e o ergonomista) de uma ferramenta, à qual se chamou Plano de Utilização das Instalações (PUI). O PUI era construído com os agricultores após a jornada de observação, a partir de uma planta baixa das instalações, já disponível na unidade de produção, que ia gradativamente sendo enriquecida com elementos pertinentes para a análise do traba-

Visando esses objetivos, realizou-se um levantamento das diretrizes legais que regem a produção de leite na França e discussões com os agricultores sobre suas demandas. Em seguida realizou-se uma jornada de observação livre em uma das unidades, a fim de compreender o trabalho e definir o escopo das observações sistemáticas nas dez unidades, assim como a dinâmica das sete jornadas de formação-ação envolvendo o coletivo de produtores. Estas são detalhadas a seguir.

\section{Jornadas de Observação e Análise do Trabalho}

Para as jornadas de observação e análise do trabalho, a metodologia utilizada foi a Análise Ergonômica do Trabalho (AET), tal como descrita por Guérin et al. (2001), consistindo em observar a atividade de trabalho do agricultor durante uma jornada inteira, que era pontuada por momentos de autoconfrontação, realizada através de entrevistas semiestruturadas.

O desenvolvimento das atividades do agricultor foi registrado com o auxílio de uma grade de observação, papel e lho, a partir das observações realizadas de antemão. Sobre este plano são representados tais elementos, a saber: aberturas (passagens, janelas), destinações de uso (diferentes categorias de animais, por exemplo), estoques e depósitos dos diferentes tipos de alimentos, estoques permanentes e intermediários de palha e feno, barreiras, cercas, etc. Uma característica importante do PUI reside na sua construção: trata-se de "animar" o plano a partir das observações e das histórias recuperadas nas jornadas de análise do trabalho, em um processo de co-construção entre o ergonomista e o agricultor. Esta co-construção favorece a apropriação cognitiva da ferramenta pelo agricultor e torna-se, assim, uma base comum para a interação destes dois atores, ligando "os atores e seus mundos" (JEANTET et al., 1996). Este PUI também seria utilizado como apoio para o trabalho com o grupo de agricultores, por ocasião das jornadas de formação-ação.

Duas ferramentas eram, então, construídas a cada jornada de observação e análise do trabalho: uma Crônica de Ação representando a jornada observada e um Plano de Uso das Instalações (PUI). Estas ferramentas, bem como as histórias 
recuperadas e as informações levantadas durante as jornadas de observação e análise do trabalho, serviriam para alimentar a discussão do grupo de agricultores por ocasião das jornadas de formação-ação.

\section{Jornadas de Formação-ação}

Nosso intuito ao propor uma formação-ação e não uma formação clássica baseava-se na idéia de que "existe na formaçãoação um objetivo de transformação das situações de trabalho que não existe necessariamente nas formações 'clássicas' (...)” (ESCOUTELOUP, MARTIN, BARTHELOT, 1996).

Trabalhou-se na mesma linha destes autores, considerandose que "o objetivo da implementação de uma formação-ação é a construção de um coletivo introduzindo o ponto de vista do trabalho nos processos de instrução das escolhas em uma empresa" (ESCOUTELOUP, MARTIN, BARTHELOT, 1996).

Para estruturar estas jornadas, pareceu importante tentar favorecer a expressão individual e coletiva dos agricultores. Buscava-se, por um lado, reforçar o enriquecimento das representações individuais sobre seu próprio trabalho e, por outro lado, contribuir para o enriquecimento da representação coletiva do trabalho agrícola portada pelo grupo, necessária para atenuar o impacto da representação social dominante.

Acreditava-se que, com a tomada da consciência coletiva e individual dos agricultores sobre a complexidade de seu trabalho, estes estariam melhor preparados para "enfrentar" os técnicos que viriam realizar o diagnóstico de adequação de suas unidades de produção às Normas Ambientais da PAC.

Havia por trás da opção pela formação-ação a mesma preocupação com da qual partilham Teiger, Laville (1989), ou seja:

“(...) a expressão dos trabalhadores tem várias funções que desempenham um papel na formação:

- Aquele de contribuir à própria elaboração da representação dos conhecimentos. O papel da palavra no processo de simbolização e no despertar do pensamento (...) é essencial na descoberta e apropriação de seus próprios conhecimentos pelos trabalhadores no seio do coletivo;

- Aquele de objetivar os problemas até então sentidos individualmente, o que torna possível em seguida o trabalho coletivo sobre a identificação das causas e das proposições de ação;

- Aquele de valorizar os conhecimentos de cada um confrontados àqueles dos outros, e/ou de os tornar relativos, o que transforma a relação com o trabalho individual e coletivo."

Procurou-se estruturar as jornadas de formação-ação de forma a apresentar características favoráveis para suscitar esta expressão coletiva, tais como:

- A manhã das jornadas de formação-ação era destinada às visitas das unidades de produção, sendo que os agricul- tores tinham a recomendação de conduzir a visita respeitando a cronologia do trabalho realizado na véspera;

- Nas tardes das jornadas de formação-ação esta mesma recomendação era dada para que o agricultor comentasse seu trabalho a partir do PUI anteriormente construído durante a jornada de observação e análise do trabalho, desenvolvida em sua unidade de produção. Com a ajuda deste plano, o agricultor e o grupo podiam reconstruir o percurso feito para cada atividade realizada (o percurso realizado pelo agricultor para alimentar as vacas leiteiras, por exemplo).

O papel dos ergonomistas consistia, sobretudo, em zelar pelo respeito à continuidade temporal, espacial e cronológica das atividades reconstituídas e conduzir a discussão até os determinantes desta configuração. Em várias ocasiões estes planos também serviram de suporte para simular outros cenários, como o acontecido em uma das jornadas, na qual o coletivo debateu idéias sobre a melhor localização para uma nova instalação destinada às novilhas, em uma das unidades de produção.

Como as jornadas de formação-ação eram muito curtas para restituir todas as questões levantadas nas jornadas de observação e análise do trabalho, introduzia-se o debate sobre o trabalho fazendo um comentário geral das crônicas das jornadas de observação e, em seguida, inseriam-se histórias escolhidas com antecedência. Estas eram lançadas situando o contexto do trabalho no dia das observações e alimentavam uma discussão-reflexão coletiva. O debate portava, então, sobre o conjunto de escolhas que poderiam ter sido feitas para evitar a ocorrência de acontecimentos "nocivos" e sobre as conseqüências a curto, médio e longo prazo, sobre a produção e a eficiência do sistema formado pela UPAF.

Nestas ocasiões, o papel dos ergonomistas consistia em incentivar a discussão sobre os elementos que compunham tal ação, tal escolha, e sobre as conseqüências desta ação ou desta escolha para o trabalho futuro, às vezes recorrendo a comparações com outras unidades de produção. Incitava-se os agricultores a continuar a discussão até tirar ensinamentos relativos a outras modalidades possíveis de instrução das escolhas técnicas e organizacionais e em relação ao que os agricultores deveriam esperar dos técnicos que lhes prestavam assistência, especialmente aqueles com os quais já interagiam (o veterinário, o controlador da cooperativa, etc.) e com os quais viriam a interagir (aqueles que viriam fazer o diagnóstico e o projeto de adequação da unidade às Normas Ambientais da PAC da CEE, dentre outros).

Procurou-se trabalhar no sentido de tornar conscientes certas estratégias que os agricultores utilizam para lidar com a complexidade, favorecendo a apropriação coletiva destas estratégias - identificadas durante as jornadas de observação e análise do trabalho e discutidas nas jornadas de formação- 
ação - chegando a usar o PUI como apoio para simular cenários de arranjos futuros, que pudessem favorecer a adoção das estratégias identificadas.

A Tabela 1 - Detalhamento das jornadas de formaçãoação, apresentada a seguir, mostra a seqüência de realização das jornadas de formação-ação, as UPAF que foram visitadas em cada uma delas e os assuntos abordados.

\section{RESULTADOS}

Os resultados aqui apresentados relacionam-se principalmente ao enriquecimento da representação que o agricultor tem de seu próprio trabalho, procurando-se elucidar como a metodologia empregada promoveu uma aproximação desta com o trabalho real, levando em conta sua complexidade.

Para tal análise, escolheu-se a tarefa supervisão do rebanho, por ser esta crucial para o bom desempenho da unidade de produção de leite de origem bovina, além de tratar-se de uma tarefa marcadamente complexa.

Pode-se afirmar que, no início da formação-ação, os agricultores falavam dessa tarefa referindo-se apenas aos momentos dedicados exclusivamente às rondas para observação do estado geral dos animais, tais como a da noite ou a do período de partos. No término da formação-ação, esta representação foi duplamente enriquecida: por um lado, pela demonstração e tomada de consciência da imbricação desta tarefa com outras, quase que permanentemente; por outro lado, pela tomada de consciência de sua complexidade, dos conhecimentos que são mobilizados, das variáveis pertinentes que são construídas, da fineza dos critérios elaborados. E, por fim, a percepção de como a destinação de uso e o arranjo espacial das instalações podem favorecer a supervisão do rebanho.

Apresenta-se a seguir a Figura 1 - Representação Gráfica da Crônica de Ação da UPAF(3), elaborada nesta unidade de produção, assim como a Figura 2 - Plano de Utilização das Instalações (PUI) da UPAF(3). Logo após, discorre-se brevemente sobre a unidade de produção chamada UPAF (3), apresentando-se então os resultados alcançados.

\section{Tabela 1: Detalhamento das jornadas de formação-ação}

\begin{tabular}{|c|c|c|}
\hline $\begin{array}{l}\text { JORNADA DE } \\
\text { FORMAÇÃO- } \\
\text { AÇÃO }\end{array}$ & UPAF VISITADAS & ASSUNTOS ABORDADOS \\
\hline 1 a & UPAF (1) & $\begin{array}{l}\text { - análise da demanda; } \\
\text { - introdução do trabalho com o PUI (plano original, enriquecimento } \\
\text { progressivo com os elementos pertinentes para a análise do } \\
\text { trabalho, representação do circuito alimentação } V L^{1} \text { ); }\end{array}$ \\
\hline $2^{a}$ & $\begin{array}{l}\text { UPAF (2) } \\
\text { UPAF (3) }\end{array}$ & $\begin{array}{l}\text { - trabalho com o PUI (reconstrução da tarefa pelo agricultor); } \\
\text { - introdução do trabalho com a crônica de ação (antecipação de } \\
\text { tarefas, planejamento; supervisão do rebanho); }\end{array}$ \\
\hline 3aㅡ & $\begin{array}{l}\text { UPAF (4) } \\
\text { UPAF (5) }\end{array}$ & $\begin{array}{l}\text { - trabalho com o PUI (novo estábulo VL na UPAF(4); } \\
\text { - trabalho com a crônica de ação (imprevistos, gestão do trabalho em } \\
\text { ambientes dinâmicos); }\end{array}$ \\
\hline $4^{\mathrm{a}}$ & $\begin{array}{l}\text { UPAF (6) } \\
\text { UPAF } 77\end{array}$ & $\begin{array}{l}\text { - trabalho com o PUI (projeto de instalação } \mathrm{GAEC}^{2} \text { na UPAF(4); } \\
\text { reformada leiteria e } \mathrm{SDO}^{3} \text { na UPAF(7); } \\
\text { - transferência de conhecimentos de pai para filho; }\end{array}$ \\
\hline 5 a & $\begin{array}{l}\text { UPAF (8) } \\
\text { UPAF (9) }\end{array}$ & $\begin{array}{l}\text { - trabalho com o PUI (possibilidades de reforma do estábulo dos } \\
\text { bezerros na UPAF(8); reforma do estábulo dos bezerros na UPAF(9); }\end{array}$ \\
\hline $6^{\underline{a}}$ & UPAF (10) & $\begin{array}{l}\text { - trabalho com representantes da } \mathrm{DDA}^{4} \text { e da } \mathrm{DSV}^{5} \text { sobre a adequação } \\
\text { das unidades de produção às normas ambientais da PAC e sobre o } \\
\text { Diagnóstico de Adequação Ambiental (DEXEL6); }\end{array}$ \\
\hline 7aㅗ & Jornada de síntese & $\begin{array}{l}\text { - apresentação dos temas discutidos durante a formação-ação; } \\
\text { - discussão e avaliação da formação-ação com os agricultores. }\end{array}$ \\
\hline
\end{tabular}

Fonte: Montedo, 2001, p. 97. 


\section{A UPAF(3}

Para favorecer a compreensão dos resultados que serão apresentados, cabe discorrer brevemente sobre a Unidade de Produção Agrícola Familiar que denominamos UPAF(3).

A unidade de produção possui uma área total de 38 hectares (ha), sendo 28 ha em torno da sede da unidade e 10 ha situados a $10 \mathrm{~km}$ de distância. Esta área possui uma quota leiteira ${ }^{7}$ de 182.000 litros. O agricultor possui um rebanho leiteiro de 36 vacas leiteiras (VL). A criação de bovinos de corte está presente através da criação de touros $^{8}$ e bois, além de vitelos provenientes do ateliê de vacas em aleitamento (VA).

O agricultor instalou-se na UPAF em 1984, onde produz leite de origem bovina e bovinos de corte. É casado, pai de três filhos com idades de seis, quatro e dois anos (à época). Sua esposa ajuda-o em tarefas pontuais na unidade de produção, embora não esteja instalada enquanto agricultora.

Em termos de equipamentos, a UPAF conta com uma sala de ordenha $2 \times 4$ (dois cais com quatro lugares), equipada com ordenhadeira mecânica e encanamentos que levam o leite até a leiteria contígua, onde se situa o tanque de resfriamento do leite. Este é recolhido a cada dois dias pelo caminhão da cooperativa.

A UPAF conta, ainda, com dois tratores, um equipamento chamado desensilador/distribuidor de palha (que tanto distribui a palha como a silagem para os animais) e um outro chamado rabot (equipamento acoplado ao trator para realizar a raspagem dos dejetos animais).

Para possibilitar ao leitor uma melhor compreensão da crônica de ação da UPAF (3), as escolhas realizadas anteriormente pelo agricultor serão discutidas brevemente, pois explicam a configuração encontrada por ocasião da realização da jornada de observação e análise do trabalho, em termos de espaços e categorias animais. Para uma melhor compreensão, a Crônica de Ação deve ser referenciada espacialmente pelo PUI correspondente.

Assim, por ocasião da jornada de observação, as categorias de animais presentes na UPAF (3) eram:

- vacas leiteiras (VL) - alojadas no estábulo VL;

- vacas secas (VS) - alojadas juntamente com as VL no estábulo VL;

- vacas em aleitamento (VA) - alojadas no estábulo VA;

Figura 1: Representação Gráfica da Crônica de Ac̣ão da UPAF(3.

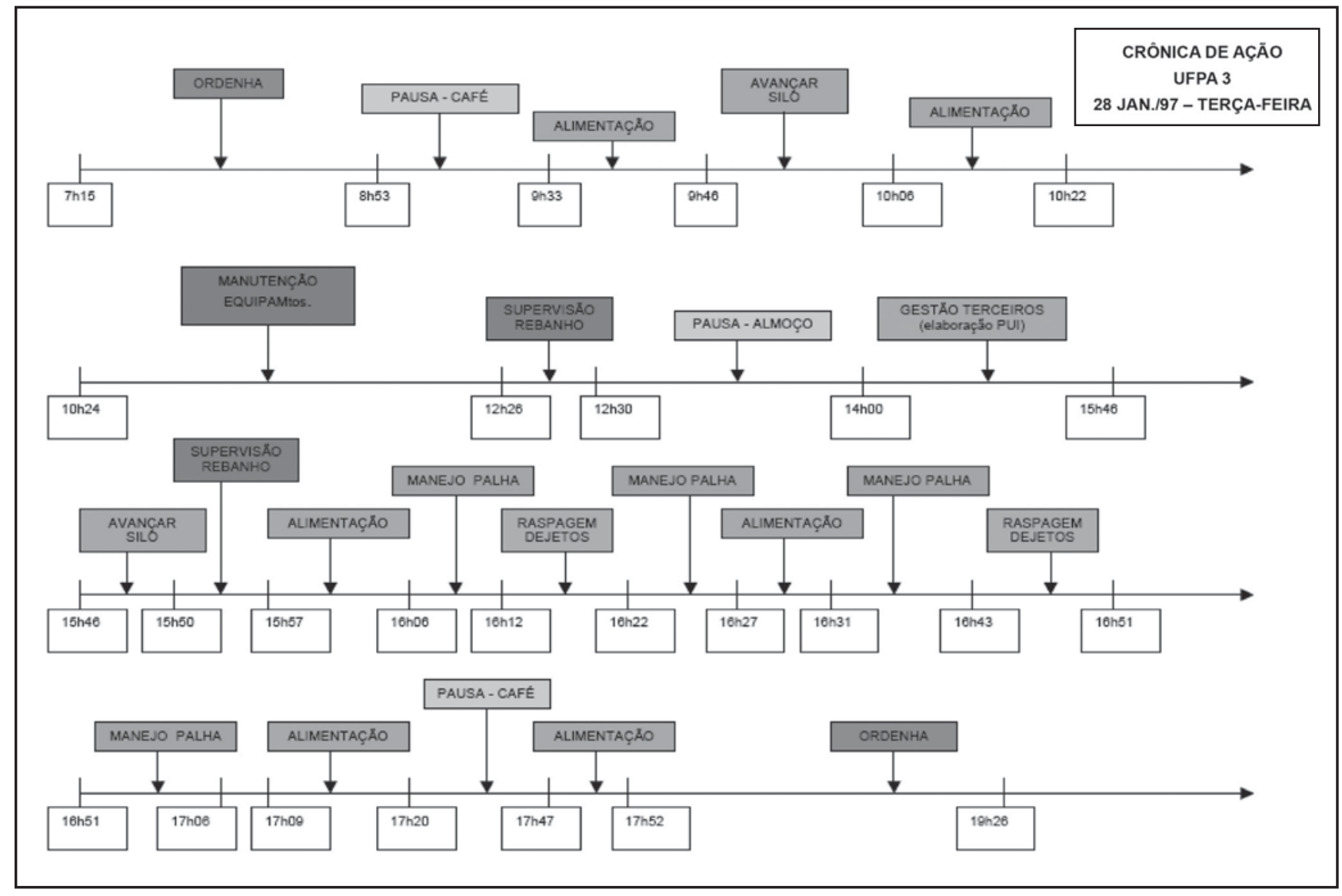


- novilhas - alojadas no estábulo novilhas;

- bezerros - alojados nos estábulos bezerros (1), (2), (3) e (4);

- touros - bovinos do sexo masculino não castrados, submetidos a um processo de engorda rápida, possibilitando a comercialização precoce; alojados no estábulo touros;

- bois - bovinos do sexo masculino castrados quando jovens, submetidos a um processo de engorda normal; alojados no estábulo bois.

Uma das características da UPAF(3) naquela época era a de haver buscado uma diversificação da produção, associando um novo ateliê de produção de carne ao de produção de leite já existente. Como a quantidade de leite que o agricultor tem direito a produzir é definida pela quota leiteira, que na prática bloqueia a possibilidade de aumento da produção, o agricultor optou por obter uma renda extra com a criação de bovinos destinados ao corte. Passou, então, a engordar os bezerros machos nascidos de suas matrizes leiteiras, destinando estes animais à engorda precoce (touros) ou à engorda normal (bois). Na época produzia apenas leite, os bezerros do sexo feminino eram criados para fins de reposição das VL de reforma (aquelas que esgotaram sua vida produtiva e são vendidas para abate). Já os bezerros do sexo masculino eram vendidos a criadores de gado bovino destinado ao corte. Logo, com a decisão de implantar um ateliê de produção de animais para corte, a lotação de bezerros na UPAF aumentou consideravelmente.

Passados alguns anos, sobreveio a ocorrência da "doença da vaca louca ${ }^{9}$ e com ela a queda vertiginosa do consumo de carne bovina em todos os países da CEE. De um momento para outro, o agricultor deparou-se com uma situação na qual seus animais (touros e bois) perderam valor rapidamente, encontrando dificuldades de comercialização. Para não ter prejuízo, o agricultor limitou ao mínimo a venda de animais de corte, inclusive os bezerros machos que antes vendia. É em parte devido a esta combinação de eventos internos e externos à UPAF que se encontra uma relativa desorganização no manejo espacial do rebanho, com quatro locais diferentes para abrigar bezerros, sendo três deles adaptados (estábulo bezerros (1), (2) e (4)).

Figura 2: Plano de Utilização das Instalações (PUI) da UPAF (3).

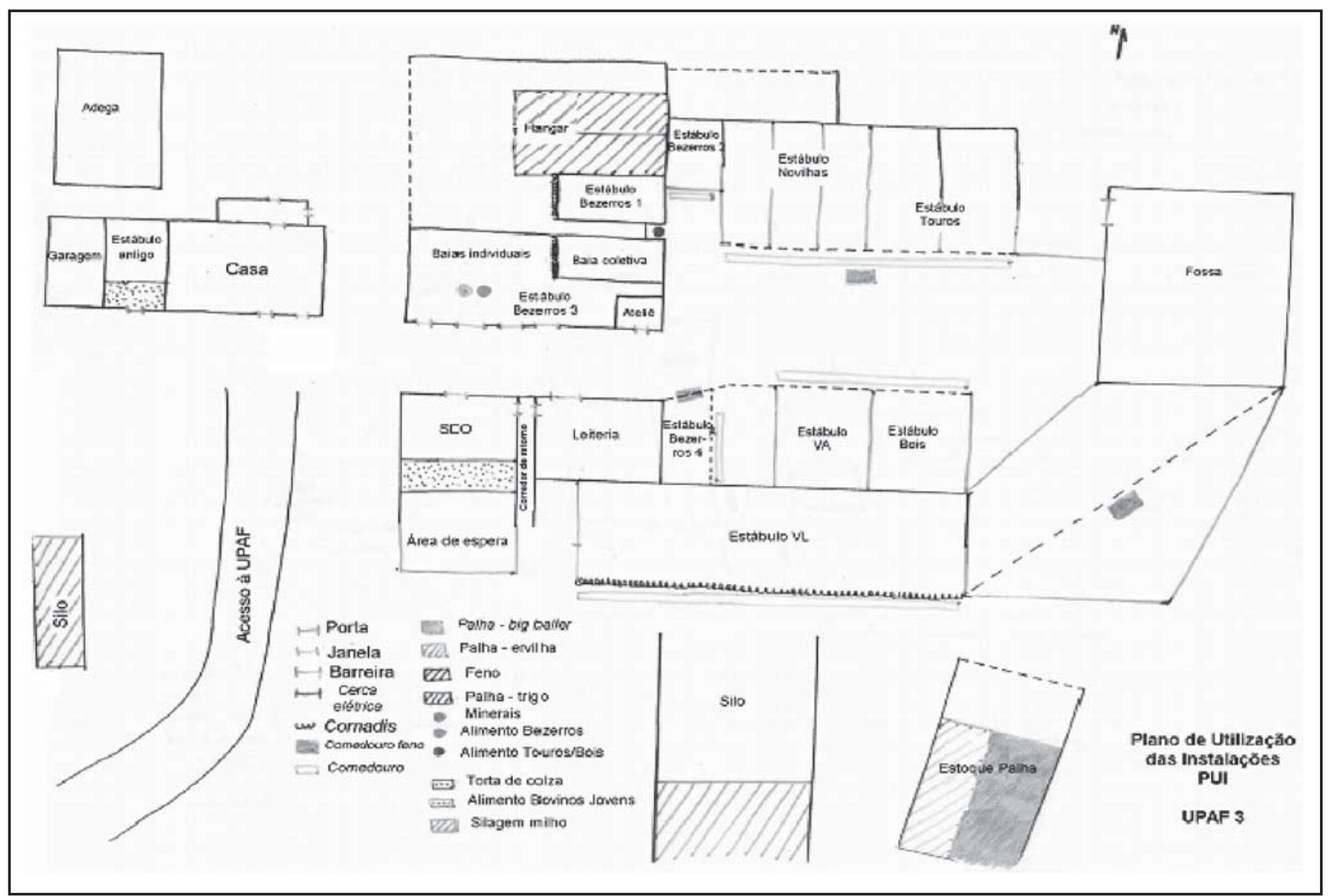

Fonte: Montedo, 2001, p.223 


\section{A Supervisão do Rebanho}

A jornada de observação e análise do trabalho na UPAF(3) foi marcada pela tarefa supervisão do rebanho, realizada com objetivos distintos de acordo com a categoria de animal observada.

Quotidianamente, ao examinar os animais presentes na UPAF, o agricultor procura identificar possíveis anormalidades, que podem ser indicadores da presença de doenças, problemas alimentares, etc.

No entanto, quando o agricultor observa as vacas leiteiras (VL), está também procurando identificar as que apresentam sinais de cio, construindo uma representação do desenvolvimento desta fase do ciclo estral, avaliando o momento adequado para chamar o inseminador e proceder à inseminação artificial. Dependendo do momento do cio no qual a VL é inseminada, existem maiores chances para que efetivamente ocorra a fecundação (e a gestação decorrente). A gestação dos bovinos dura aproximadamente 285 dias (9,5 meses), podendo variar fisiologicamente em 15 dias para mais ou para menos, dependendo da raça, idade, tamanho do bezerro, condições externas, etc.

Neste segmento, discutir-se-á com maior profundidade um aspecto da supervisão do rebanho: de que forma o agricultor realiza a supervisão das VL e decide o momento de chamar o inseminador. Desta sua escolha depende a ocorrência da prenhez da VL, com conseqüências óbvias no desempenho da UPAF.

Para que se possa melhor compreender a complexidade da tarefa "supervisão do rebanho", iniciar-se-á com uma explicação a respeito da fisiologia reprodutiva dos bovinos, em especial sobre o ciclo estral das fêmeas. Em seguida, serão apresentados os resultados relativos à crônica de ação da UPAF(3.

O ciclo estral da fêmea bovina e o momento ideal para proceder à inseminação artificial $^{10}$

O ciclo estral da fêmea bovina é formado por quatro fases: pré-cio, cio, pós-cio e anestro. A cada 21 dias, em média, a fêmea "entra em cio", sendo que este período pode variar fisiologicamente entre 17 e 24 dias. Esta variação depende de fatores como idade do animal, alimentação, raça, etc.

O pré-cio tem duração aproximada de três dias e neste período as vacas começam a apresentar sinais de alteração comportamental; estes são mais intensos no período que antecede o cio (4 a 10 horas). Os sinais apresentados pela vaca nesta fase são: inquietação, nervosismo, cauda erguida, urina freqüente, vulva inchada e brilhante, comportamento de disputa com outras vacas (cabeça com cabeça), diminuição do apetite, mugir constantemente, liberação de muco vaginal (que deve ser cristalino e transparente), diminuição da produção de leite, tendência ao agrupamento com outros animais e o mais importante deles - pois relativamente identificado com maior facilidade pelo agricultor - a fêmea monta em outras fêmeas, mas ainda não se deixa montar. agricultor introjeta o ponto de vista dominante
na sociedade sobre o seu trabalho: aquele de que há pouca necessidade de atividade intelectual para a realização de sua atividade profissional. Isto faz com que a complexidade de sua atividade e as estratégias que adota para realizá-la permaneçam tácitas, ou até inconscientes, não sendo objeto de verbalização e apropriação coletiva por parte dos agricultores.

O cio é um fenômeno fisiológico caracterizado principalmente pelas mudanças no comportamento das vacas. A sua duração depende em grande parte da raça do animal, encontrando-se para os bovinos de origem européia uma duração entre 6 e 18 horas. Os sintomas do cio são muito semelhantes aos do pré-cio, com a diferença de que a fêmea aceita ser montada pelas outras fêmeas. Pode-se afirmar que uma determinada fêmea está no cio se ela estiver aceitando a monta. Cabe acrescentar que a maioria das fêmeas entra em cio à noite e de madrugada, sendo observadas em cio pela manhã.

O pós-cio é a fase do ciclo quando a fêmea já não mais aceita monta e na qual todos os sinais citados anteriormente já não acontecem mais. A fêmea volta a comportar-se normalmente, desinteressando-se pelas outras fêmeas do rebanho e voltando a se alimentar normalmente. É nesta fase que ocorre a ovulação, entre 6 a 12 horas após o final do cio.

A quarta e última fase do ciclo estral é o anestro fisiológico, que se caracteriza por um período de repouso sexual e tem duração de aproximadamente 14 dias em fêmeas com idade reprodutiva.

O momento ideal para realizar a inseminação artificial é, portanto, o final do cio, caracterizado pela ocasião em que a fêmea não mais aceita a monta, ou seja, recusa ser montada. 
Ela apresenta um período relativamente longo de alta fertilidade algumas horas antes e após o término do cio.

$\mathrm{Na}$ prática, a recomendação dada aos agricultores é a seguinte:

- As vacas observadas em cio (aceitando a monta) pela manhã, deverão ser inseminadas na tarde do mesmo dia;

- As vacas observadas em cio à tarde, deverão ser inseminadas na manhã do dia seguinte, bem cedo.

De acordo com este esquema, em ambas as situações as vacas estarão sendo inseminadas próximo ao final do cio, portanto, em um período de alta fertilidade.

A supervisão do rebanho, a detecção do cio e o momento adequado para chamar o inseminador

Durante a crônica de ação da UPAF(3), encontram-se dez momentos nos quais o agricultor realiza a supervisão do rebanho, totalizando um tempo de 30 minutos $(4,33 \%$ do tempo total de duração da jornada). Estes 30 minutos englobariam tanto os momentos nos quais o agricultor realiza exclusivamente a supervisão do rebanho, tal qual a ronda no estábulo VL entre $12 \mathrm{~h} 26$ e $12 \mathrm{~h} 30$, como aqueles em que o agricultor realiza a supervisão do rebanho concomitantemente à realização de outra(s) tarefa(s). (Ver Quadro 1: Tempo diário dedicado aos subsistemas) um papel o cio de três VL as quais deverão ser inseminadas na manhã seguinte.

Foi neste momento que o ergonomista percebeu a real dimensão da tarefa supervisão das VL, que deveria ter sido muito mais importante do que os episódios de supervisão identificados até então, a saber: a ronda das $12 \mathrm{~h} 26$ às $12 \mathrm{~h} 30$ e o período no qual o agricultor permanece em frente ao estábulo VL para observar os animais que ali se encontram (15h50 às 15h57).

Entrevistando o agricultor, identificou-se que sua preocupação com a supervisão das VL iniciara-se na realidade durante a ordenha da manhã, a qual constitui um momento privilegiado para observação dos animais, pois as VL "desfilam" uma a uma diante do agricultor. Assim, durante a ordenha, ele pôde observar individualmente as VL, identificando sinais de cio, tais como o aspecto da vulva e o seu comportamento em relação às demais companheiras de rebanho na área de espera. Quando o agricultor sobe à área de espera para procurar as vacas secas (VS) e tocá-las para a Sala de Ordenha (SDO) (8h12), realiza um breve momento de observação das VL que já foram ordenhadas e estão no estábulo VL, procurando identificar sinais comportamentais que confirmem a suspeita de cio (8h13).

Mais adiante, ao realizar a tarefa avançar silo de milho (9h46 às 10h05) o agricultor continua a fazer simultaneamente a supervisão das VL, uma vez que o silo de milho localiza-se em frente ao estábulo VL, favorecendo esta simultaneidade. Avançando um pouco mais na jornada, após consertar o rabot $^{11}$, o agricultor realiza a ronda de supervisão das VL propriamente dita, entre $12 \mathrm{~h} 26$ e 12 h30. Apesar de já estar atrasado para o almoço, o agricultor realiza assim mesmo a ronda, pois ainda não estava seguro em relação à fase do cio na qual se encontravam as $\mathrm{VL}$, e conseqüentemente não havia ainda decidido se chamaria o inseminador para a tarde do mesmo dia ou para a manhã seguinte.

No período da tarde, o agricultor

Se apenas 4,33\% do tempo total de duração da jornada foram dedicados à "supervisão do rebanho", por qual razão afirma-se que esta jornada foi marcada por esta tarefa?

Em primeiro lugar, cabe colocar que este tempo está subestimado. Essa afirmação tem origem na ação realizada pelo agricultor exatamente às $17 \mathrm{~h} 16$, quando se dirige à leiteria e faz dois tipos de anotações: marca no quadro de planejamento do rebanho o cio de uma VL, a qual deverá ser observada novamente dentro de três semanas; marca em retorna ao silo de milho para finalizar a tarefa "avançar silo de milho" (15h46 às 15h50) - com o auxílio de sua esposa ele dobra a lona que lá havia ficado pela manhã. Aproveitando novamente a localização espacial do silo de milho, o agricultor procede mais um período de observação, ao mesmo tempo em que executa a tarefa relacionada à lona do silo, a fim de precisar quais VL estavam no cio e em qual fase se encontravam (montando nas outras ou deixando-se montar). Após finalizar a tarefa avançar silo de milho e julgando ser 


\begin{tabular}{|c|c|c|c|c|c|c|c|c|c|c|c|c|c|c|c|}
\hline 是高 & & & & & & & & & & & & & శ్ & 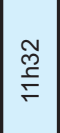 & 음 \\
\hline 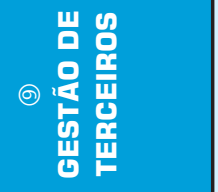 & 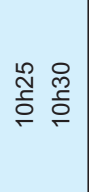 & $\mid$ & & & & & & & & & & & $\risingdotseq$ & $\stackrel{\sqrt[5]{5}}{\stackrel{5}{5}}$ & 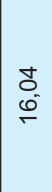 \\
\hline (2) & 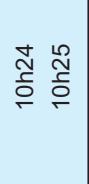 & ભ & & & & & & & & & & & 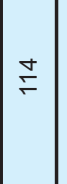 & $\stackrel{\stackrel{t}{\circ}}{\rightleftharpoons}$ & $\begin{array}{l}\hat{f} \\
\stackrel{0}{C}\end{array}$ \\
\hline 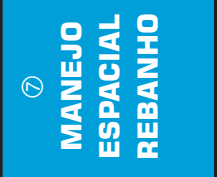 & $\underset{\infty}{\stackrel{\Gamma}{\infty}}$ & $\stackrel{\infty}{\sum_{\infty}^{\infty}}$ & & & & & & & & & & & N & $\begin{array}{l}\widetilde{o} \\
\text { ธे }\end{array}$ & ্ָ \\
\hline 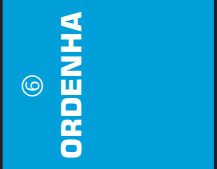 & 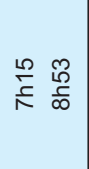 & 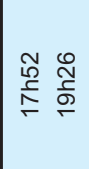 & & & & & & & & & & & 吕 & 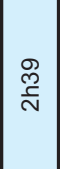 & $\begin{array}{l}\infty \\
\stackrel{\infty}{N} \\
\text { N }\end{array}$ \\
\hline 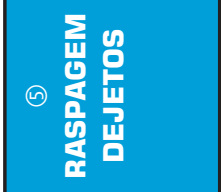 & 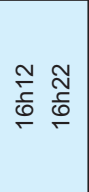 & 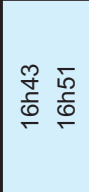 & & & & & & & & & & & $\stackrel{\infty}{\circ}$ & $\stackrel{\infty}{\frac{\infty}{\delta}}$ & $\stackrel{\circ}{i}$ \\
\hline 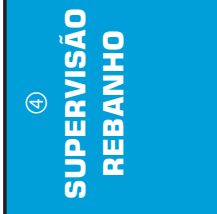 & $\stackrel{O}{\stackrel{N}{K}}$ & $\sum_{\infty}^{\frac{m}{c}}$ & $\underset{\substack{\infty \\
\infty}}{\stackrel{\infty}{\infty}}$ & $\stackrel{\circ}{\frac{9}{5}}$ & 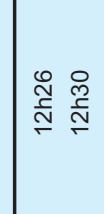 & 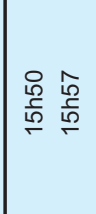 & 怘 & 을 옳 & 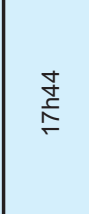 & 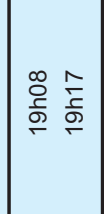 & & & ৪ & $\begin{array}{l}\stackrel{o}{y} \\
\text { g. }\end{array}$ & $\underset{\infty}{\infty}$ \\
\hline 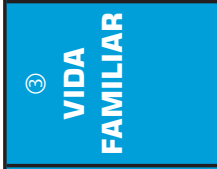 & 怘 $\frac{\substack{\infty \\
\infty}}{\infty}$ & 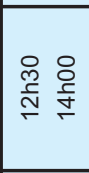 & 㣽等 & & & & & & & & & & $\bar{N}$ & 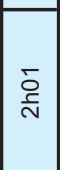 & 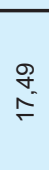 \\
\hline 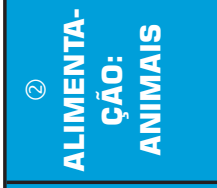 & 寜 $\frac{\bar{c}}{\infty}$ & 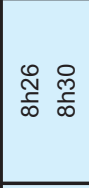 & 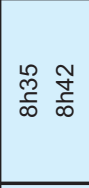 & $\begin{array}{ll}\text { m } & \stackrel{0}{1} \\
\text { के } & \text { के }\end{array}$ & 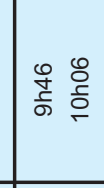 & 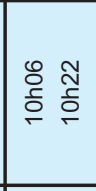 & 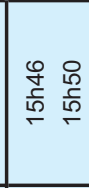 & 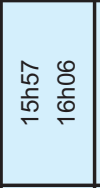 & 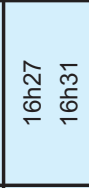 & 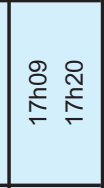 & 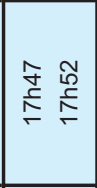 & \begin{tabular}{|l}
$\stackrel{\circ}{\circ}$ \\
के \\
के \\
$\stackrel{5}{\sigma}$
\end{tabular} & ณ & 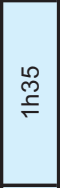 & 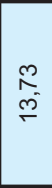 \\
\hline 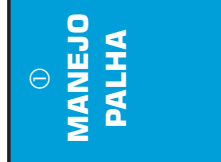 & 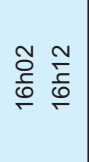 & 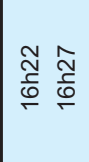 & 总 & 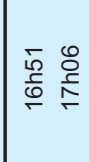 & $\underset{\stackrel{M}{E}}{\stackrel{M}{E}}$ & & & & & & & & ซ & $\mid \begin{array}{l}\mathfrak{y} \\
\tilde{z} \\
\bar{z}\end{array}$ & $\begin{array}{l}\hat{0} \\
0^{\circ}\end{array}$ \\
\hline 焉 & \multirow{2}{*}{\multicolumn{12}{|c|}{ 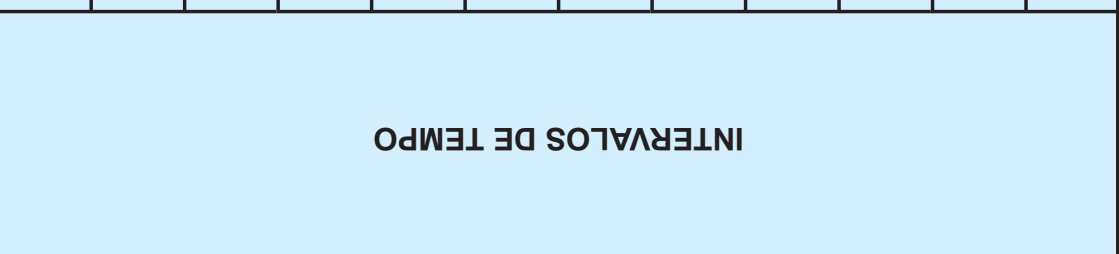 }} & \begin{tabular}{|l|}
0 \\
$o$ \\
5 \\
$\Sigma$ \\
$\Sigma$ \\
\end{tabular} & 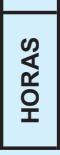 & $\therefore$ \\
\hline $\begin{array}{l}\text { क } \\
\text { 兽 } \\
\text { क }\end{array}$ & & & & & & & & & & & & & & 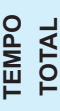 & \\
\hline
\end{tabular}


ainda preciso uma melhor supervisão, o agricultor detém-se durante sete minutos a observar o comportamento das VL no estábulo (15h50 às 15h57).

Assim, às 17h16, quando faz as anotações identificando as quatro VL que estão no cio, o agricultor já construiu um diagnóstico preciso a respeito do momento do cio em que elas se encontram, e conseqüentemente decidiu quando proceder à inseminação. Preferiu inseminar três VL e deixou outra repetir o cio. $\mathrm{O}$ agricultor, então, telefona para o inseminador solicitando que passe na manhã do dia seguinte para realizar a inseminação de três das quatro VL cujo cio foi identificado.

Agrícola Comum (PAC) da Comunidade Econômica Européia (CEE).

Sabendo-se que a quota leiteira impõe uma limitação da quantidade de leite a ser produzida durante o ano agrícola (agosto a julho), existe uma gestão realizada pelos produtores de leite, cujo objetivo é manter a produção anual sem ultrapassar a quantidade de litros determinada. O agricultor relatou estar em momento de redução da produção para não ultrapassar a sua quota até o final do ano.

Associada à gestão da quota, existe a situação de relativa desorganização espacial na UPAF em função da lotação de animais, já que a sua comercialização, especialmente a de animais de corte, encontrava-se suspensa. Nesta situação, o agricultor preferiu deixar a VL repetir o cio, atrasando a gestação em três semanas aproximadamente e, com isso, atrasando também o nascimento do bezerro, de forma a não sobrecarregar ainda mais a UPAF em termos de lotação de animais.

\section{estabelecendo um compromisso entre elas, re-avaliando permanentemente as informações que possui, definindo estratégias e exercitando o pensamento complexo.}

\section{Discussão dos Resultados Apresentados}

O conjunto de resultados obtidos junto aos agricultores demonstra que a tarefa supervisão do rebanho é "imbricada por excelência” em várias outras (MONTE-

Relembrando a orientação prática que é dada aos agricultores e apresentada anteriormente, o produtor observara que as VL, pela manhã, estavam montando umas nas outras, mas ainda não aceitavam a monta. No período da tarde, o comportamento das VL mudara para a aceitação da monta, indicando que a fase de pós-cio - momento ideal para a inseminação - ocorreria na manhã do dia seguinte. A dificuldade de precisão do diagnóstico, razão dos repetidos momentos de supervisão, está certamente ligada ao número de VL apresentando sinais de cio simultaneamente e à dificuldade de uma identificação precisa dos animais fora da ordenha, especialmente ao serem observados a certa distância, como quando o agricultor realiza a tarefa "avançar o silo".

A quarta VL, cujo cio foi anotado no quadro de planejamento do rebanho, ficou para ser observada dentro de três semanas (21 dias), quando ela deverá repetir o cio. Por que razão o agricultor não aproveitou e determinou também a inseminação desta VL?

Para entender esta escolha, é preciso voltar ao que foi colocado no início da apresentação dos resultados relativos à crônica de ação da UPAF(3), a respeito da mudança de orientação da produção em função das transformações desencadeadas pelo advento da "doença da vaca louca" e também acerca da quota leiteira instituída pela Política
DO, 2001). Analisando-se a crônica de ação da UPAF(3), percebe-se que esta tarefa aparece imbricada nas demais tarefas executadas pelo agricultor, desde que a localização espacial assim o permita.

Resgatando-se o que foi colocado sobre a metodologia e ao tratar dos resultados obtidos na formação-ação com os agricultores franceses, afirma-se que, no início, eles não tinham plena consciência da imbricação da tarefa supervisão do rebanho com as demais, sendo que sua representação foi enriquecida no decorrer da intervenção. Esta tomada de consciência foi importante no sentido de poder antecipar esta imbricação, por ocasião do projeto de adequação das unidades de produção às normas ambientais da PAC, favorecendo-a através do arranjo espacial das instalações.

Às vezes, a simples presença de janelas no estábulo de bezerros permite ao agricultor observar as VL no estábulo a elas destinado, enquanto alimenta os bezerros, favorecendo a observação do comportamento do grupo de VL, fundamental para a supervisão do rebanho. Ou, como na UPAF (3), na qual a supervisão do rebanho foi favorecida pela localização do silo, em frente ao estábulo das vacas leiteiras (VL), podendo o agricultor desenvolver a atividade "avançar silo de milho" e simultaneamente realizar a observação do comportamento destes animais de forma a identificar quais estavam no cio e, mais especificamente, em qual fase do cio. $\mathrm{O}$ fato 
de haver deixado a lona para terminar de enrolar à tarde, com a ajuda da esposa, favoreceu novamente a observação dos animais e a conseqüente tomada de decisão de chamar o inseminador para a manhã seguinte. O que pode aos olhos do leigo parecer desleixo, na verdade constitui mais uma estratégia do agricultor: pela manhã a esposa estaria ocupada preparando o almoço e não poderia ajudá-lo a enrolar a lona que cobria o silo; no período da tarde ela estaria disponível e o comportamento dos animais já teria evoluído, demonstrando com maior certeza o desenvolvimento das fases do cio das quatro VL envolvidas.

Para finalizar a discussão dos resultados faz-se necessário realizar um exercício de compreensão da decisão tomada pelo agricultor da UPAF(3), ao solicitar a inseminação de três dentre as quatro VL cujo cio identificara, fazendo com que uma delas viesse a repetir o cio.

A racionalidade básica por trás de toda unidade de produção agrícola é a racionalidade da produção, significando para a UPAF(3) aumentar a quantidade de litros de leite produzida ou a quantidade de arrobas de bovinos de corte comercializada.

De acordo com esta racionalidade, deixar uma VL repetir o cio significa prejuízo, pois estar-se-ia diminuindo a quantidade de bezerros/VL/ano, e conseqüentemente a quantidade de litros de leite produzida ou o número de animais de corte a comercializar. Ao deixar a VL repetir o cio, o agricultor estaria contrariando a racionalidade da produção.

No entanto, esta não foi a única racionalidade levada em consideração pelo agricultor em sua decisão: outra por ele considerada foi a da gestão da quota leiteira. Como o final do ano agrícola estava se aproximando e o agricultor sabia já ter produzido a maior parte da quota à qual tem direito, a estratégia configurava-se em diminuir o ritmo da produção de leite para não ultrapassar sua quota, uma vez que a produção excedente é penalizada em termos de preço. O agricultor estabelece então um compromisso entre a racionalidade da produção e a da gestão da quota leiteira, o que o leva a diminuir o ritmo de produção de leite, significando um número reduzido de partos naquela época.

Outra racionalidade presente neste compromisso é aquela relativa ao mercado europeu de carne bovina, na época em retração devido à ocorrência da doença da vaca louca. Diminuir a produção de animais de corte e gerir a lotação de animais na UPAF passa a ser mais importante no momento do que continuar a produzir no mesmo ritmo e encontrar dificuldades para vender a produção.

Assim, esta decisão envolve um compromisso entre, no mínimo, três racionalidades distintas: a da produção, a da gestão da quota leiteira e a do mercado europeu de carne bovina. Esta situação mostra que o trabalho do agricultor passa pela gestão de uma diversidade de racionalidades presentes na situação de trabalho, e que ele estabelece um compromisso entre elas, reavaliando permanentemente as informações que possui, definindo estratégias e exercitando o pensamento complexo.

\section{DISCUSSÃO FINAL}

A metodologia adotada - especialmente as jornadas de observação e análise do trabalho nas quais se realizou a AET e produziu-se a Crônica de Ação e o PUI - mostrou-se eficaz para o enriquecimento da representação que o agricultor tem de seu próprio trabalho, aproximando-a do trabalho real. Momento privilegiado para tal foi a co-construção do PUI pelo ergonomista e pelo agricultor, favorecendo a apropriação cognitiva da ferramenta em questão e permitindo a comunicação entre os atores envolvidos.

Privilegiou-se o olhar complexo sobre a situação de trabalho procurando identificar, em conjunto com o agricultor, seus elementos constitutivos, as racionalidades através das quais estes elementos se manifestam, as variabilidades inerentes ao trabalho agrícola, além das estratégias adotadas. Eliminou-se qualquer tentativa de simplificação do trabalho real ou de enquadramento da atividade de trabalho em regras gerais de funcionamento, evitando-se a desagregação da realidade complexa do trabalho agrícola familiar.

Através do processo de enriquecimento da representação do trabalho, fortaleceu-se a posição do agricultor enquanto piloto de seu projeto, fornecendo um instrumento intermediário de concepção - o PUI - que poderá ser utilizado no planejamento de futuros desenvolvimentos das unidades de produção.

\section{Artigo recebido em 31/01/2006 Aprovado para publicação em 22/08/2007}




\section{- Referências}

ESCOUTELOUP, J.; MARTIN, C.; BARTHELOT, F. La formation-action estelle une intervention? In: PATESSON, R. (Dir.) Intervenir par l'ergonomie. Bruxelles: SELF, v. 2, p. 307-310, 1996.

GUÉRIN, F.; LAVILLE, A.; DANIELLOU, F.; DURAFFOURG, J.; KERGUELEN, A. Compreender o trabalho para transformálo: a prática da ergonomia. São Paulo: Edgard Blücher, 200 p., 2001.
5. DSV - Direção de Sanidade e Vigilância Animal

6. DEXEL - Diagnóstico Ambiental da Unidade Produtora de Animais

7. A quota leiteira foi instituída pela PAC em 1985 para controlar os excedentes de produção de leite e seus derivados, como uma das políticas de controle de preços e estoques de produtos agrícolas no âmbito da CEE.

8. Refere-se aos taurillons, no entanto, utilizar-se-á a palavra « touros » por não haver correspondente mais adequado na língua portuguesa.
9. Doença da Vaca Louca - trata-se da Encefalopatia Espongiforme Bovina (BSE).

10. Disponível em: < www.inseminacaoartificial.com.br/fisiologia.htm > . Acesso em: 20 mar:/2000

11. Trata-se de um equipamento que, acoplado ao trator, é utilizado para raspar os dejetos dos animais.

\section{- Sobre os autores}

Uiara Bandineli Montedo, Dr. Eng.

Depto. Engenharia de Produção/Escola Politécnica/USP

Professora Doutora

End.: Av. Prof. Almeida Prado, Trav. 2, no 128 - 05508-090 - Cidade Universitária - São Paulo/SP

Tel.:: (11) 3091-5363 ramal 335

Fax: (11) 3091-5399

E-mail: uiara.montedo@gmail.com

\section{Laerte Idal Sznelwar, Dr. Ergonomie}

Depto. Engenharia de Produção/Escola Politécnica/USP

Professor Doutor

End.: Av. Prof. Almeida Prado, Trav. 2, nº 128 - 05508-090 - Cidade Universitária - São Paulo/SP

Tel.: (11) 3091-5363 ramal 477

Fax: (11) 3091-5399

E-mail: laertesz@usp.br 